\title{
Metafora Bahasa Aceh pada Komentar Akun Instagram @tercyduck.aceh
}

\author{
Rahmad Nuthihar ${ }^{\bowtie}$, Riza Hasan ${ }^{2}$, RN Herman ${ }^{3}$, Mursyidin $^{4}, \&$ Wahdaniah $^{5}$ \\ ${ }^{1,2}$ Akademi Komunitas Negeri Aceh Barat, Meulaboh, Aceh \\ ${ }^{3}$ Universitas Syiah Kuala, Banda Aceh, Aceh \\ ${ }^{4}$ Universitas Malikussaleh, Lhokseumawe, Aceh \\ ${ }^{5}$ Politeknik Negeri Lhokseumawe, Lhokseumawe, Aceh \\ ${ }^{1}$ rahmad.nuthihar@aknacehbarat.ac.id
}

\begin{abstract}
This article discusses the Acehnese metaphor found in the comment column on @ tercyduk.aceh Instagram account. This research aimed to investigae the types of metaphors used by Instagram users when giving comments. The data source of this research was obtained from the comment column on @tercyduk.aceh Instagram account, since the data used for this research were comments containing metaphors. This research was a qualitative type with a qualitative descriptive approach. The data collection was conducted by reading and note-taking techniques. The data processing was carried out through the stages of data selection, data presentation, and conclusion. The results of this research implie that structural metaphor was used to express a concept transferred to another one, while orientational metaphor was used to say things related to the orientation of human experience. Furthermore, ontological metaphors were based on events. The numbers and types of metaphors found in this research were 10 ontological metaphors, 8 structural metaphors, and 6 orientational metaphors. The metaphor used by Instagram users also led to swearing words. The cause was since metaphors were a style of language to articulate something without its actual meaning, but as a figure of speech based on similarities or comparisons.
\end{abstract}

Keywords: structural metaphor, orientational metaphor, ontological metaphor, aceh language

Abstrak : Artikel ini membahas metafora bahasa Aceh yang terdapat pada komentar akun Instagram @tercyduk.aceh. Penelitian ini bertujuan menemukan jenis metafora yang dipakai oleh pengguna Instagram saat memberikan komentar. Sumber data penelitian ini diperoleh pada kolom komentar akun Instagram @tercyduk.aceh sementara yang dijadikan data penelitian ini adalah komentar yang mengandung metafora. Penelitian ini berjenis kualitatif dengan pendekatan deskriptif kualitatif. Pengumpulan data dilakukan dengan teknik baca dan catat. Pengolah data dilakukan dengan tahapan seleksi data, penyajian data, dan penarikan simpulan. Hasil penelitian ini menyimpulkan bahwa metafora struktural dipakai untuk mengatakan suatu konsep ditransfer dengan menggunakan konsep yang lain, sementara metafora orientasional dipakai untuk mengatakan hal-hal yang berhubungan dengan orientasi pengalaman manusia. Selanjutnya, metafora ontologis didasarkan atas kejadian. Jumlah metafora yang ditemukan dalam penelitian ini yakni, metafora ontologis sebanyak 10, metafora struktural 8, dan

http://ejournal.iainbengkulu.ac.id/index.php/disastra

Copyright () 2021 Disastra: Jurnal Pendidikan Bahasa dan Sastra Indonesia

All rights reserved 
metafora orientasional 6. Penelitian ini juga menemukan bahwa untuk mendukung ataupun memperkuat gagasan metafora dipakai emotikon pada bagian akhir komentar. Selain itu, metafora yang digunakan oleh pengguna Instagram juga mengarah pada kata makian. Hal itu disebabkan metafora merupakan salah satu gaya bahasa untuk mengatakan kata atau kelompok kata bukan dengan arti yang sebenarnya, melainkan sebagai lukisan yang berdasarkan persamaan atau perbandingan.

Kata Kunci : metafora struktural, metafora orientasional, metafora ontologis, bahasa aceh

\section{Pendahuluan}

Media sosial Instagram banyak digunakan oleh masyarakat Indonesia terutama pada kalangan remaja (Indika \& Jovita, 2017). Tren penggunaan Instagram disebabkan informasi yang diperoleh didukung dengan ilustrasi gambar ataupun video sehingga menarik minat para pengguna telepon genggam untuk mengikuti akun-akun informasi. Komentar para pengguna Instagram cenderung beragam, ada yang menanggapi suatu postingan dengan komentar positif, negatif, sinis, bahkan ada juga beragam metafora yang ditulis oleh pengguna Instagram untuk menanggapi postingan. Selain itu, para pengguna Instagram juga menggunakan emotikon dan meme yang merupakan salah satu fenomena penyampaian pesan dalam bentuk baru dengan menggabungkan bahasa verbal dengan komunikasi nonverbal (ekspresi) (Pramiyanti \& Christin, 2014; Nugraha, dkk. 2015).

Penggunaan bahasa menarik dikaji pada komentar Instagram. Hal itu disebabkan media Instagram yang sifatnya dua arah memungkinkan para pengguna berbalas komentar. Begitu juga halnya dengan penggunaan bahasa. Fitur berupa emotikon cenderung digunakan oleh pengguna Instagram untuk mendukung gagasan yang ditulisnya. Selain itu, para pengguna Instagram cenderung cermat dalam hal pemilihan kata terutama untuk memperhalus makna. Hal ini sesuai dengan penelitian Eliya (2017) yang menyimpulkan bahwa Penggunaan pilihan kata yang bermakna eufemisme seolah memperhalus apa yang hendak disampaikan.

Penelitian ini membahas penggunaan metafora bahasa Aceh oleh para pengguna Instagram. Pemilihan akun Instagram @tercyduck.aceh sebagai sumber data karena akun tersebut diikuti oleh 1.360 pengguna Instagram. Pemilihan topik metafora bahasa Aceh menarik untuk dibahas karena bahasa Aceh dominan digunakan oleh pengguna Instagram yang berbahasa Ibu bahasa Aceh untuk memberikan komentar pada Instagram. Selanjutnya, komentar bahasa Aceh tersebut cenderung terdapat metafora. Hal itu disebabkan merupakan gaya bahasa yang berfungsi untuk mengilustrasikan suatu benda, sifat, wujud dengan menggunakan istilah yang berbentuk abstrak (Keraf, 2009:82). Untuk menafsirkan makna metafora tersebut dibutuhkan pemahaman berkaitan dengan pragmatik sehingga tidak cukup dengan kajian semantik. Selain itu, penafsiran makna metafora juga erat kaitannya dengan sosiopragmatik sebab metafora yang ada pada suatu daerah akan berbeda sesuai dengan budaya masingmasing. Hal ini sesuai dengan pendapat Bustomi (2019) yang mengatakan setiap 
bangsa memiliki budaya dan karakter berbeda-beda yang berpengaruh terhadap kegiatan berbahasa sehari-hari. Pada masyarakat Aceh, binatang sering dijadikan sebagai perbandingan sehingga metafora dalam bahasa Aceh berupa kelas kata nomina banyak yang berkaitan dengan binatang (Azwardi, 2017; Mursyidin et al., 2020).

Tujuan penelitian ini untuk menemukan struktur metafora yang sering digunakan masyarakat Aceh dalam berkomunikasi sebab sudah menjadi kebiasaan orang Aceh menggunakan bahasa metafora dalam karya sastra (Harun, dkk. 2020). Diasumsikan pengaruh metafora dalam karya sastra membuat para elite di Aceh merasa lumrah mengungkapkan sesuatu dengan bahasa metafora.

Fokus penelitian ini menemukan jenis metafora pada akun Instagram @tercyduck.aceh berdasarkan teori Lakoff. Dalam teori tersebut dijelaskan terdapat tiga jenis metafora, yakni (1) metafora ontologis, (2) metafora struktural, dan (3) metafora orientasional (Lakoff and Johnsen, 2003).

(a) Metafora struktural adalah metafora struktural suatu konsep ditransfer dengan menggunakan konsep yang lain.

(b) Metafora orientasional berhubungan dengan orientasi pengalaman manusia, seperti naik-turun (up-down), dalamluar (in-out), depan-belakang (frontback), hidup-mati (on-off), dalamdangkal (deep-shal-low), dan pusatkeliling (central-peripheral) (Haula \& Nur, 2019).

(c) Metafora ontologis adalah metafora yang didasarkan atas kejadian, aktivitas emosi yang dirasakan manusia. Hal ini sesuai dengan temuan penelitian Dewi, Astuti, \& Novita (2020) yang
Volume 3, Nomor 2, Juli 2021

ISSN 2655-3031 (P), 2655-7851 (O)

DOI: http://dx.doi.org/10.29300/disastra.v3i2.4364

menyimpulkan bahwa metafora ontologis di dalamnya terdapat gaya bahasa personifikasi. Adapun temuan penelitian ini berupa maja ontologis adalah sebagai berikut.

Penggunaan bahasa metafora merupakan kunci memperhalus makna. Hal ini juga berkaitan dengan budaya suatu komunitas masyarakat (Genovesi, 2020). Ditinjau berdasarkan bentuk, metafora terdiri atas frasa, kata majemuk, dan idiom dibangun oleh konstruksi unsur bagian tubuh + unsur lain dan unsur lain + unsur bagian tubuh (Lyra, 2016). Unsur-unsur tersebut akan menjadi fokus permasalahan dalam analisis data kajian ini.

Sejauh ini, ada beberapa penelitian terbaru berkenaan dengan kajian metafora dalam kebahasaan. Kajian-kajian tersebut merupakan kajian yang relevan dengan kajian ini. Kajian-kajian tersebut antara lain pernah dilakukan oleh Harun, dkk. (2020) dengan judul Figurative Language Used in A Novel by Arafat Nur on The Aceh Conflict (Kasetsart Journal of Social Sciences, 2020); Genovesi (2020) dengan judul Metaphor and What is Meant: Metaphorical Content, What is Said, and Contextualism (Journal of Pragmatics, 2020); Haula \& Nur (2019) dengan judul Konseptualisasi Metafora dalam Rubrik Opini KOMPAS: Kajian Semantik Kognitif (Jurnal Retorika, 2019); Ray (2019) dengan judul Analisis Jenis-jenis Metafora dalam Surat Kabar.

Berdasarkan hasil penelusuran belum ditemukan kajian yang fokus pada ungkapan metafora bahasa Aceh pada media Instagram. Oleh karenanya, kajian ini penting dilakukan sebagai referensi keilmuan sekaligus sebagai pengetahuan kebaruan dalam komunikasi sosial. 
Metode Penelitian

Jenis penelitian ini adalah kualitatif dengan pendekatan deskriptif kualititafi karena data dan pembahasan penelitian dijabarkan dalam rangkaian kata. Data penelitian diambil pada media sosial Instagram pada akun @tercyduck.aceh. Pemilihan sumber data pada media akun Instragam @tercyduck.aceh karena postingan dari@tercyduck.aceh mendapat respons terutama komentar yang beragam dari pengguna Instagram di Aceh. Selain itu, akun tersebut diikuti oleh 136rb pengguna Instagram.

Pengumpulan data dilakukan dengan teknik baca dan catat dengan tahapan (1) membaca keseluruhan komentar para akun Instagran (2) menyeleksi komentar yang mengandung metafora, (3) menabulasi data yang terdapat metafora. Komentar para pengguna Instagram yang dikumpulkan pada akun @tercyduck.aceh merupakan
Volume 3, Nomor 2, Juli 2021

ISSN 2655-3031 (P), 2655-7851 (O)

DOI: http://dx.doi.org/10.29300/disastra.v3i2.4364 2021. Penganalisisan data dilakukan dengan tahapan seleksi data, penyajian data, dan penarikan simpulan. Analisis metafora merujuk pada teori Lakoff dan Johnsen (2003) yang membagi metafora menjadi tiga, yakni metafora struktural, metafora orientasional, dan metafora ontologis.

\section{Hasil dan Pembahasan}

Para pengguna Instagram lazim menggunakan metafora untuk memberikan komentar terkait postingan dari tercyduck.aceh. Metafora yang digunakan oleh pengguna dominan adalah metafora ontologis sebanyak 10 , metafora struktural 8, dan metafora orientasional 6 .

Metafora bahasa Aceh yang terdapat dalam komentar Instagram pada akun tercyduck.aceh sangatlah banyak. Akan tetapi, yang disajikan dalam data penelitian ini adalah sebagai berikut.

Tabel 1. Kode, Konteks, Data, dan Jenis Metafora

\begin{tabular}{|c|c|c|c|}
\hline Kode & Konteks & Data & Jenis Metafora \\
\hline \multirow{4}{*}{ A } & \multirow{3}{*}{$\begin{array}{l}\text { Tercyduck.aceh } \\
\text { membagikan } \\
\text { postingan } \\
\text { mengenai tindak } \\
\text { kejahatan yang } \\
\text { menyebabkan } \\
\text { korban meninggal } \\
\text { dunia. Pelaku }\end{array}$} & $\begin{array}{l}\text { 1. Pu obat kuat lom nek siblah aki ka lama } \\
\text { kubu } \text { ? (Apa obat kuat kek, sebelah kaki } \\
\text { sudah dalam kubur) }\end{array}$ & metafora ontologis \\
\hline & & $\begin{array}{l}\text { 2. Kdang boh hana ccok ngen ubat } \\
\text { (kadang pen*** tidak cocok dengan obat) }\end{array}$ & metafora ontologis \\
\hline & & $\begin{array}{l}\text { 3. Gara2 ALee/sibuyung han ditem beudoh } \\
\text { kepeu ta ancan.. cukop dijinakkan saja } \\
\text { pasti trbang buyung nya.. (-) atau speed } \\
\text { jih kdang ka kureung (Gara-gara alu } \\
\text { Sibuyung tidak mau ereksi mengapa } \\
\text { harus mengancam. Cukup jinakan saja } \\
\text { pasti terbang burugnya. Ataupun } \\
\text { kecepatannya mulai berkurang) }\end{array}$ & metafora struktural \\
\hline & $\begin{array}{l}\text { Sumber: } \\
\text { shorturl.at/jCWX6 }\end{array}$ & $\begin{array}{l}\text { 4. Padahai ata jen apret nyan hana } \\
\text { dibeudoh le..yak peugah obat kuat } \\
\text { gop...gop geu meukat ka meuthon2..ka } \\
\text { tuha are..nyan baro takalen ureng pungo } \\
\text { peugah hana manjur ubat gop..cit katak }\end{array}$ & $\begin{array}{l}\text { Metafora } \\
\text { orientasional }\end{array}$ \\
\hline
\end{tabular}

Rahmad Nuthihar, Riza Hasan, RN Herman, Mursyidin, Wahdaniah Metafora Bahasa Aceh pada Komentar Akun Instagram @ Tercyduck Aceh 


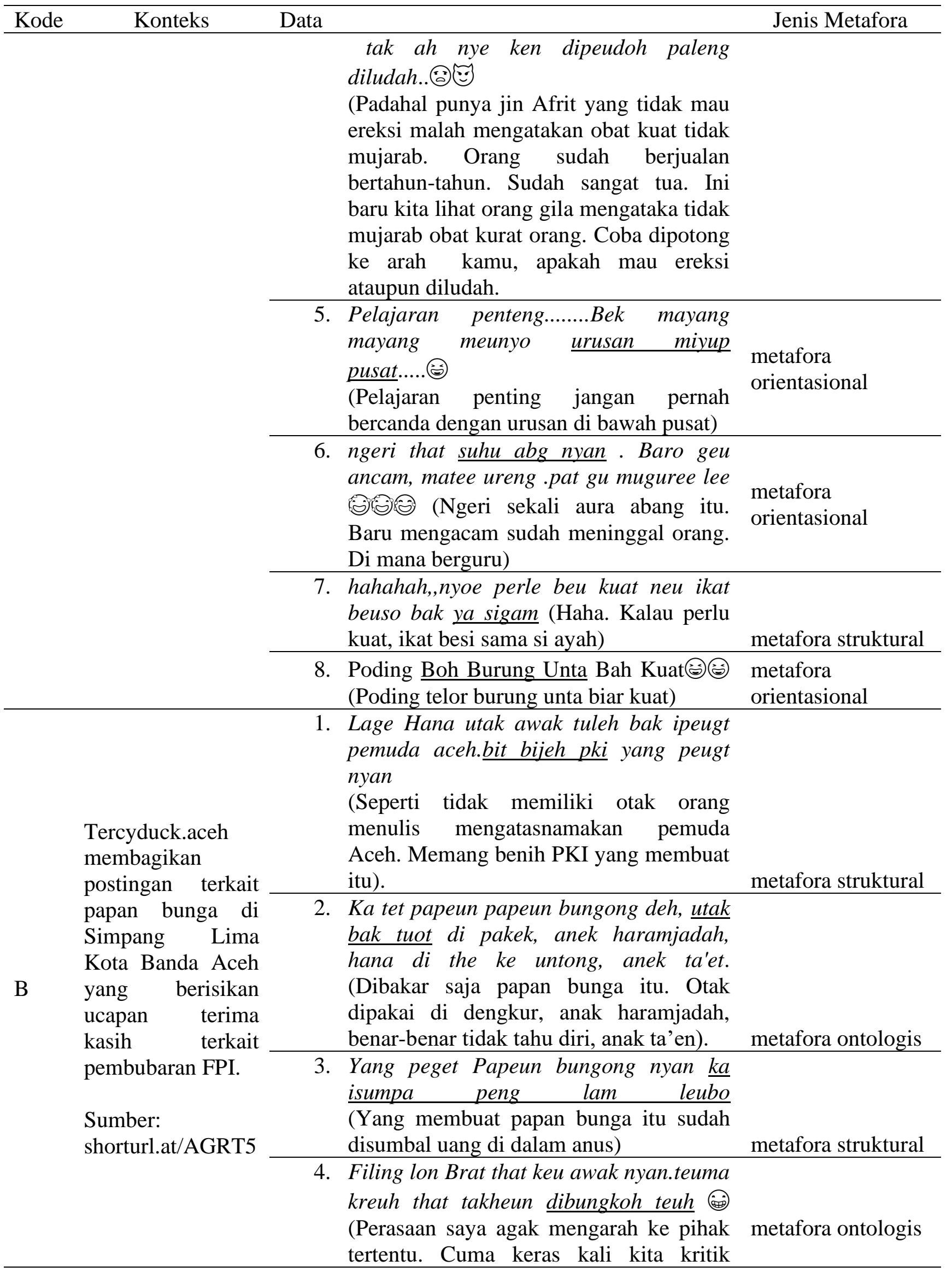

Rahmad Nuthihar, Riza Hasan, RN Herman, Mursyidin, Wahdaniah Metafora Bahasa Aceh pada Komentar Akun Instagram @ Tercyduck Aceh 


\begin{tabular}{llll}
\hline Kode & Konteks & Data & Jenis Metafora \\
\hline & & dibungkus nanti)
\end{tabular}

5. Buii. Behe behe bui.. Model seruduk lam supot tngoh sepi . Leuh seruduk plueng.. Bit akai buiii...

(Babi. Benar-benar bai. Model seruduk dalam sepi. Selesai menyeruduk langsung pergi. Memang akal babi)

metafora

orientasional

1. Akibat terlalu mengejar lifestyle, padahai rumoh digampong $k a$ singet (;)

Tercyduck.aceh membagikan postingan terkait penipuan pembelian HP. Pelaku penipuan

C tersebut mengirimkan bukti transfer palsu ke pemiliki toko HP.

Sumber: shorturl.at/kzLPW (Akibat terlalu banyak mengejar gaya hidup. Padahal, rumah di kampung sudah miring)

2. Abeih lagee demi apel teukap? ?장 (Habis metafora gaya demi apel digigi) struktural

3. Hana Buutt Jak Mitaa Buutt尺िAkhee Buutt Lam Hotel Prodeo..BerGaya BolhLah Genk Tp Tolol Jngann (Tidak ada kerjaan cari kerjaan. Akhirnya dalam hotel prodeo. Bergayalah genk tapi metafora ontologis jangan tolol)

1. Kajeut asah parang lajuu nyan maseng2. (Masing-masing sudah boleh mengasah parang)

2. Lon lawet nyoe sehat" mantong ..Hana payah sinvak sivak nyan ..ku sedekah bak awak suntik mantong uenteuk, Pat teuepeu kenong jackpot (Saya selama ini masih sehat. Gak perlu sinvak sivak itu. Saya sedekahkan untuk orang suntik nanti. Mana tahu dapat jakpot).

metafora ontologis

3. Tanyoe Hana karona di Aceh, beik jak pena pena... (Kita di Aceh tidak ada

Tercyduck.aceh membagikan postingan terkait rencana Pemerinta Aceh yang akan melakukan vaksinasi kepada 3,3 juta warga Aceh. Corona. Jangan dibuat-buat) metafora struktural

4. Meunyoe ka razia masker masker Mantong bek yak culok racon lam badan gop

(Bila Razia, cuku razia masker saja metafora jangan masukkan racun ke tubuh orang) struktural

5. Han lon tem, lon takot lagee kejadian bak Drakor Sweet Home. Aleuh disuntik jeut ke monster@? (Saya tidak mau takut seperti kejadian di drama korea Sweet

Sumber: shorturl.at/hizFL Home sesudah disuntuk menjadi monster) metafora ontologis 


\begin{tabular}{|c|c|c|c|}
\hline Kode & \multirow{4}{*}{$\begin{array}{c}\text { Konteks } \\
\text { Tercyduck.aceh } \\
\text { membagikan } \\
\text { postingan } \\
\text { mengenai seorang } \\
\text { calon pengantin } \\
\text { pria yang } \\
\text { menerobos banjir } \\
\text { untuk menuju } \\
\text { pesta pada rumah } \\
\text { pengantin } \\
\text { wanita }\end{array}$} & Data & Jenis Metafora \\
\hline \multirow{3}{*}{$\mathrm{E}$} & & $\begin{array}{l}\text { 1. menyo bak but pajoh apam lam lam } \\
\text { banjir jadeh ()) ()) ()) ()) (): (Kalau 'makan } \\
\text { apam', dalam banjir pun jadi }\end{array}$ & metafora struktural \\
\hline & & $\begin{array}{l}\text { 2. Pane na jeut kendo nyan sibak rukok } \\
\text { treuk katrok u bulen. } \\
\text { goyang. Satu batang rokok lagi 'sampai } \\
\text { ke bulan' }\end{array}$ & $\begin{array}{l}\text { metafora } \\
\text { orientasional }\end{array}$ \\
\hline & & & \\
\hline
\end{tabular}

Sumber:

3. Meu susah Ngon gop.... Kamalam sep

shorturl.at/aADOY

Dua geuhes (Susah dengan orang, waktu malam berdaua saja)

metafora ontologis

Sesuai dengan tabel 1.1 di atas, ditemukan bahwa metafora digunakan oleh pengguna Instagram untuk sebagai bahasa kiasan. Hal ini sesuai dengan penelitian yang dilakukan oleh Subagyo (2014) yang menyimpulkan bahwa fungsi metafora adalah untuk mengiaskan.

Berbeda halnya dengan penelitian yang dilakukan oleh Haula \& Nur (2019) yang lebih fokus mengkaji jenis metafora berdasarkan Lakoff \& Johnsen (2003). Pemilihan jenis metafora tersebut sama halnya dengan pembahasan dari penelitian ini yang fokus mengkaji pada metafora struktural, metafora orientasional, dan metafora ontologis.

\section{a) Metafora Struktural}

Terdapat 8 metafora struktural dalam dalam komentar akun Instagram @ tercyduk.aceh. Pengklasi-fikasian metafora struktural tersebut karena komentar para pengguna Instagram berisi konsep ditransfer dengan menggunakan konsep yang lain.

Data I
Gara2 ALee/sibuyung han ditem beudoh kepeu ta ancan.. cukop dijinakkan saja pasti trbang buyung nya.. (5) atau speed jih kdang $k a$ kureung.

(Gara-gara alai Sibuyung tidak mau ereksi mengapa harus mengancam. Cukup jinakan saja pasti terbang burugnya. Ataupun kecepatannya mulai berkurang) [A.1]

Pada data tersebut metafora struktural ditandai dengan frasa ALee/sibuyung. Jika diterjemahkan dalam bahasa Indonesia bermakna alai si Buyung. ALee/sibuyung bukanlah makna konkret melainkan konotasi dari alat kelamin pada laki-laki. Metafora dengan bentuk nonima tersebut diklasifikasikan dalam metafora struktural karena mencoba mengiaskan makna denotasi dengan konsep lainnya.

Penggunaan metafora pada A.1 juga didukung dengan penggunaan emotikon menangis (今). Penggunaan emotikon tersebut bermaksud sindiran terhadap terhadap perilaku oknum sebagaimana yang diposting tercyduk.aceh. 
Data II

Lage Hana utak awak tuleh bak ipeugt pemuda aceh.bit bijeh pki yang peugt nyan

(Seperti tidak memiliki otak orang menulis mengatasnamakan pemuda Aceh. Memang benih PKI yang membuat itu). [B.1]

Metafora struktural pada Data II ditandai dengan frasa bijeh pki._Bijeh pki dalam bahasa Indonesia bermakna benih PKI. Dikategorikan dalam metafora struktural karena metafora struktural merupakan sebuah konsep dibentuk secara metaforis dari satu konsep ke konsep lain yang didasarkan pada dua ranah, yaitu ranah sumber ( $\mathrm{RSu}$ ) dan ranah sasaran (RSa). Ranah sumber pada metafora tersebut adalah bijeh, sedangkan sasaran adalah $p k i$.

\section{b) Metafora orientasional}

Hasil penelitian ini menemukan 6 metafora orientasional dalam komentar akun Instagram @ tercyduk.aceh. Penggunaan metafora orientasional salah satunya bertujuan mengiaskan sesuatu yang konkret menjadi abstrak yang didasari atas pengalaman. Hal ini terlihat pada data III dan data IV sebagai berikut.

\section{Data III}

Padahai ata jen apret nyan hana dibeudoh le..yak peugah obat kuat gop...gop geu meukat ka meuthon2..ka tuha are..nyan baro takalen ureng pungo peugah hana manjur ubat gop..cit katak ata kah nye ken dipeudoh paleng diludah..:(2) Padahal punya jin Afrit yang tidak mau ereksi malah mengatakan obat kuat tidak mujarab. Orang sudah berjualan bertahun-tahun. Sudah sangat tua. Ini baru kita lihat orang gila mengataka
Volume 3, Nomor 2, Juli 2021

ISSN 2655-3031 (P), 2655-7851 (O)

DOI: http://dx.doi.org/10.29300/disastra.v3i2.4364

tidak mujarab obat kurat orang. Coba dipotong ke arah kamu, apakah mau ereksi ataupun diludah. [A.4]

Metafora orientasional pada data III ditandai dengan frasa jen apret 'jin affrit'. Dikategorikan frasa jen apret ke dalam metafora orientasional karena didasari atas pengalaman bahwa jin afrit merupakan jin yang paling jahat dibandingkan jin lainnya.

\section{Data IV}

Buii. Behe behe bui.. Model seruduk lam supot tngoh sepi. Leuh seruduk plueng.. Bit akai buiii

(Babi. Berani babi. Model seruduk dalam sepi. Selesai menyeruduk langsung pergi. Memang akal babi) [B.3]

Metafora orientasional juga terdapat pada data IV yang ditandai dengan frasa Behe behe bui 'berani babi'. Dikategorikan metafora orientasional karena babi merupakan binatang yang paling dibenci oleh manusia dan suka menyerang lawan di saat sepi.

Selain metafora orientasional yang ditandai dengan frasa Behe behe bui, pada data tersebut juga terdapat emotikon

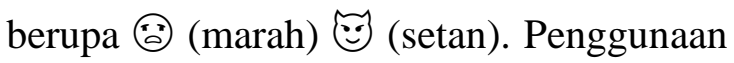
emotikon tersebut dianggap relevan oleh pengguna Instagram untuk memberikan tanggapa terkait konteks postingan berupa oknum yang mengancam penjual obat.

\section{c) Metafora Ontologis}

Terdapat 10 metafora ontologis dalam komentar akun Instagram @ tercyduk.aceh. Pengklasifikasian dalam metafora ontologis disebabkan oleh komentar pengguna Instagram didasarkan

Rahmad Nuthihar, Riza Hasan, RN Herman, Mursyidin, Wahdaniah 
atas kejadian, aktivitas emosi yang dirasakan manusia

\section{Data V}

$P u$ obat kuat lom nek siblah aki ka lama kubu ?

(Apa obat kuat kek, sebelah kaki sudah dalam kubur) [A.1].

Data V dikategorikan dalam metafora ontologis karena frasa siblah aki ka lama kubu yang bermakna 'sebelah kaki sudah dalam kubur' merupakan emosi yang dirasakan manusia terkait konteks komentar tersebut. Pengguna Instagram memberikan komentar tersebut karena pelaku sudah berusia lanjut sehingga memberikan komentar siblah aki ka lama kubu. Metafora ontologis juga terdapat dalam skema citra eksistensi 'excistence' jenis proses 'process'. Hal ini terlihat pada data VI.

\section{Data VI}

Filing lon Brat that keu awak nyan.teuma kreuh that takheun

\section{dibungkoh teuh (i)}

(Perasaan saya agak mengarah ke pihak tertentu. Cuma keras kali kita kritik dibungkus nanti) [B.4].

Data VI dikategorikan dalam metafora ontologis karena frasa dibungkoh teuh 'dibungkus nanti' merupakan skema citra eksistensi 'excistence' jenis proses 'process'. Pada metofora tersebut juga terdapat emotikon (;i) (senang) untuk memperkuat/mendukung komentar dalam bentuk kontradiktif. Hal itu disebabkan seharusnya emotikon yang dipakai adalah emotikon sedih, tetapi pengguna Instagram menggunakan emotikon senang. Ini
Volume 3, Nomor 2, Juli 2021

ISSN 2655-3031 (P), 2655-7851 (O)

DOI: http://dx.doi.org/10.29300/disastra.v3i2.4364

membuktikan emotikon tersebut tidak hanya relevan dengan pernyataan dalam komentar tetapi bisa juga dalam bentuk kontra.

Data VII

Meu susah Ngon gop.... Kamalam sep

\section{Dua geuh:s}

(Susah dengan orang, waktu malam cukup berdua) [E.3].

Metafora ontologis pada data VII ditandai dengan klausa Kamalam sep Dua geuh yang bermakna 'waktu malam cukup berdua'. Dikategorikan dalam metafora ontologis karena penanda metafora tersebut merupakan pengalaman dari pemberi komentar. Hal itu sesuai dengan konteks postingan tersebut terkait seorang laki-laki yang dinaikkan becak untuk pergi ke pernikahan.

\section{Simpulan}

Komentar para pengguna Instagram terdapat metafora struktural, orientasional, dan ontologis. Adapun jumlah metafora yang ditemukan dalam penelitian ini yakni, metafora ontologis sebanyak 10, metafora struktural 8 , dan metafora orientasional 6.

Penggunaan metafora tersebut berfungsi sebagai kiasan ataupun mengatakan yang abstrak terhadap postingan. Metafora tersebut dipakai sebagai penghalus makna sehingga tidak mengarah pada kata makian ataupun umpatan. Hal ini disebabkan, lazimnya untuk menanggapi sebuah postingan masyarakat Aceh menggunakan interjeksi untuk merespons suatu berita yang dianggap unik.

Metafora struktural dipakai untuk mengatakan suatu konsep ditransfer 


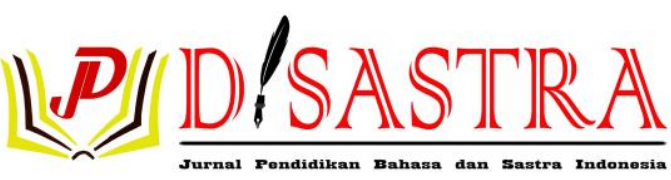

dengan menggunakan konsep yang lain sementara metafora orientasional dipakai untuk mengatakan hal-hal yang berhubungan dengan orientasi pengalaman manusia. Selanjutnya, metafora ontologis didasarkan atas kejadian.

Hasil penelitian ini juga menyimpulkan bahwa untuk memperkuat ataupun agar terkesan dua arah, diberikan emotikon. Emotikon yang ditemukan dalam penelitian ini antara lain, (s) (menanggis), (:) (senyum), ] (tertawa sambil menangis), : (marah), (-) (setan), (malu). Penggunaan emotikon tersebut salah satunya adalah untuk mendukung komentar para pengguna Instagram.

\section{Ucapan Terima Kasih}

Terima kasih kami ucapkan kepada Kementerian Riset Teknologi/Badan Riset dan Inovasi Nasional Republik Indonesia yang telah mendanai penelitian ini dengan nomor kontrak 001 /SP2H/LT/DRPM/2021.

\section{Daftar Pustaka}

Aulia, Z. N. and Nur, T. (2020) 'Metafora Konseptual dalam Rubrik UnakAnik Kahirupan Majalah Online Manglé : Analisis Semantik Kognitif', Lokabasa, 11(2), pp. 226236. doi: 10.17509/jlb.v11i2.25251.

Azwardi (2017) Binatang dalam Peribahasa Aceh. Jakarta: Badan Pengembangan dan Pembinaan Bahasa Kementerian Pendidikan dan Kebudayaan.

Bustomi, B. (2019) 'Wajah Bangsa dalam Cermin Budaya Berbahasa', Disastra: Jurnal Pendidikan Bahasa dan Sastra Indonesia, 1(2), p. 17. doi: 10.29300/disastra.v1i2.2054.
Volume 3, Nomor 2, Juli 2021

ISSN 2655-3031 (P), 2655-7851 (O)

DOI: http://dx.doi.org/10.29300/disastra.v3i2.4364

Dewi, F. P. K., Astuti, P. P. and Novita, S. (2020) 'Metafora dalam Lirik Lagu Agnez Mo: Kajian Semantik', Asas: Jurnal Sastra, 9(2), pp. 72-80.

Eliya, I. (2017) 'Eufemisme dan Disfemisme dalam Catatan Najwa â€ œ Darah Muda Daerahâ€: Pola, Bentuk, dan Makna', Deiksis: Jurnal Pendidikan Bahasa dan Sastra Indonesia, 4(2), pp. 22-30.

Genovesi, C. (2020) 'Metaphor and What is Meant: Metaphorical Content, What is Said, and Contextualism', Journal of Pragmatics, 157, pp. 17-38. doi: https://doi.org/10.1016/j.pragma.201 9.11.002.

Harun, M., Qismullah Yusuf, Y. and Karnafi, M. (2020) 'Figurative Language Used in A Novel By Arafat Nur on The Aceh Conflict', Kasetsart Journal of Social Sciences, 41(2), pp. 395-400. doi: 10.34044/j.kjss.2020.41.2.12.

Haula, B. and Nur, T. (2019) 'Konseptualisasi Metafora dalam Rubrik Opini Kompas: Kajian Semantik Kognitif', RETORIKA: Jurnal Bahasa, Sastra, dan Pengajarannya, 12(1), p. 25. doi: 10.26858/retorika.v12i1.7375.

Idris, M. (2019) 'Metafora dalam Kebudayaan Islam Melayu Sumatera Selatan', Kalpataru, 5(2), pp. 126140.

Indika, D. R. and Jovita, C. (2017) 'Media Sosial Instagram Sebagai Sarana Promosi untuk Meningkatkan Minat Beli Konsumen', Jurnal Bisnis Terapan, 1(1), pp. 25-32.

Keraf, G. (2009) Diksi dan Gaya Bahasa [Diction and Language Style]. Jakarta: Gramedia Pustaka Utama.

Rahmad Nuthihar, Riza Hasan, RN Herman, Mursyidin, Wahdaniah Metafora Bahasa Aceh pada Komentar Akun Instagram @ Tercyduck Aceh 
Lakoff, G. and Johnsen, M. (2003) Metaphors We Live By. Chicago: The University of Chicago.

Lyra, H. M. (2016) 'Peranti Lingual Metafora Orientasional Bagian Tubuh dalam Bahasa Sunda', Riksa Bahasa, 2(1), pp. 42-47.

Mursyidin et al. (2020) 'Understanding Acehnese Proverbs and Their Relation to the Community Work Ethics', IJELR: International Journal of Education, Language and Religion, 02(1), pp. 11-16.

Nugraha, A., Sudrajat, R. H. and Putri, B. P. S. (2015) 'Fenomena Meme di Media Sosial: Studi Etnografi Virtual Posting Meme pada Pengguna Media Sosial Instagram', Jurnal Sosioteknologi, 14(3), pp. 237-245.

Pramiyanti, A. and Christin, M. (2014) 'Makna Simbol Emotikon dalam Komunitas Kaskus', Jurnal Sosioteknologi, 13(2), pp. 113-119.

Purnomo, A. C. and Muhibbin, A. (2018)
Volume 3, Nomor 2, Juli 2021

ISSN 2655-3031 (P), 2655-7851 (O)

DOI: http://dx.doi.org/10.29300/disastra.v3i2.4364

Analisis Semiotika Terhadap Penggunaan Emoticon Whatsapp dalam Komunikasi Interpersonal antar Mahasiswa Ilmu Komunikasi Angkatan 2013. Universitas Muhammadiyah Surakarta.

Ray, S. A. (2019) 'Analisis Jenis-jenis Metafora dalam Surat Kabar: Kajian Semantik [Analysis of Types of Metaphor Types in Letters: Semantic Studies]', Jurnal Pendidikan Bahasa dan Sastra Indonesia, 3(2), pp. 146150. Available at: https://journal.unnes.ac.id/sju/index. php/jpbsi/article/view/20226.

Subagyo, P. A. (2002) 'Metafora dalam Wacana Tajuk Tentang Terorisme di Harian Kompas dan Koran Tempo', Jurnal Ilmiah Kebudayaan SINTESIS, 8(1), pp. 35-43.

Wiradharma, G. and WS., A. T. (2016) 'Metafora dalam Lirik Lagu Dangdut: Kajian Semantik Kognitif', Arkhais, 7(1), pp. 5-14. doi: 10.30742/sv.v1i2.737.

Rahmad Nuthihar, Riza Hasan, RN Herman, Mursyidin, Wahdaniah 